\title{
Fifteen phase transmission line protection using daubechies-4 wavelet transform
}

\author{
Gaurav Kapoor \\ Department of Electrical Engineering, Modi Institute of Technology, Kota, Rajasthan, INDIA \\ Corresponding Author: e-mail: gaurav.kapoor019@gmail.com, Mobile: +91-9166868988 \\ ORCID iD: http://orcid.org/0000-0002-5432-8699
}

\begin{abstract}
In this work, the daubechies-4 wavelet transform (Db4WT) is utilized for fault detection and faulted phase recognition in a fifteen phase transmission line (FPTL). The daubechies-4 wavelet transform has been widely investigated using the MATLAB model of a $765 \mathrm{kV}, 200 \mathrm{~km}$ long fifteen phase transmission line. The fifteen phase fault currents measured by the current measurements blocks connected at the bus-1 of the fifteen phase transmission line are entered to the wavelet transform algorithm. The first level detail coefficients of the fifteen phase currents are then calculated. The fault detection is carried out with great correctness.
\end{abstract}

Keywords: fault detection, faulty phase recognition, fifteen phase transmission line protection, wavelet transform.

DOI: http://dx.doi.org/10.4314/ijest.v12i1.1

\section{Introduction}

The chance of fault occurrence on the fifteen-phase transmission line is more when comparing with the six-phase transmission line. Thus, exact detection of the faults in the fifteen-phase transmission line turns out to be very influential for extenuating the loss of gain and providing rapid renovates.

Quite a few newly reported research studies addressed the issues related to fault detection and classification in transmission lines. Some important research efforts are reported in brief in this section. A fault detection technique based on wavelet transform for series capacitor compensated double circuit transmission line has been proposed in (Gautam et al., 2018). Wavelet transform has been applied for the protection of a $400 \mathrm{kV}$ series capacitor compensated double circuit transmission line (Gautam et al., 2018). Hilbert Huang transform has been used for the detection and classification of single line to ground near-in and far-end faults in a $138 \mathrm{kV}$ six-phase transmission line (Kapoor, 2019). Wavelet transform based protection technique has been presented for the detection of inter-circuit and cross-country faults in a $400 \mathrm{kV}$ series capacitor compensated double circuit transmission line (Kapoor, 2019). In (Kapoor, 2019), discrete Walsh Hadamard transform has been used for the protection of wind farm connected series capacitor compensated three phase transmission line. Hilbert Huang transform based three phase to ground fault detection and classification scheme has been presented in (Kapoor, 2019) for the protection of a $138 \mathrm{kV}$ six-phase transmission line. A wavelet transform based fault detection of phase to phase faults in a six-phase series capacitor compensated transmission line has reported in (Kapoor, 2018). Mathematical morphology has been applied for the detection of near-in and remote-end faults in sixphase transmission line (Kapoor, 2018). A discrete wavelet transform based protection technique has been proposed for the twelve -phase series compensated transmission line (Kapoor, 2018). A discrete wavelet transform based fault location method has been proposed for the three terminal transmission line (Kapoor, 2018). A wavelet transform based fault detector has been proposed for series capacitor compensated three phase transmission line (Kapoor, 2018). Detection and classification of multi-location three phase to ground faults in a twelve phase transmission line using wavelet transform has been reported in (Kapoor, 2018). Discrete wavelet transform has been used for the location of faults in a $330 \mathrm{kV}$ three phase transmission line (Kapoor, 2018). Detection of phase to phase faults in a series capacitor compensated six-phase transmission line using wavelet transform has been presented in 
(Kapoor, 2018). Detection and classification of near-in and far-end faults in a six-phase transmission line using wavelet transform has been reported in (Kapoor, 2018). A combination of modular artificial neural network and wavelet transform has been used for the recognition of faulty zone and fault location in six-phase transmission line (Koley et al., 2017). Haar wavelet transform in conjunction with the artificial neural network has been for the classification of phase to phase to faults in a six-phase transmission line (Kumar et al., 2014). Walsh Hadamard transform has been used for the detection of faults in a series capacitor compensated transmission line (Sharma et al., 2018). Mathematical morphology has been utilized for the boundary protection of a six-phase transmission line (Sharma et al., 2017). A numerical relay based over-current protection technique has been proposed for a sixphase transmission line (Warathe and Patel, 2015).

In this work, a daubechies-4 wavelet transform (Db4WT) is executed for the detection and classification of faults in a fifteenphase transmission line. Such type of research has not been depicted so far to the best of the information of the author. The results points up that the Db4WT capably detects the faults, and the consistency of the Db4WT is not susceptible to the variations in the fault factors.

This article is structured as: Section 2 presents the specifications of fifteen-phase transmission line. Section 3 describes the process for fault detection using Db4WT. Section 4 reports the simulation results of the investigations carried out in this study. Section 5 concludes the article.

\section{The Specifications of Fifteen-Phase Transmission Line}

Figure 1 shows the schematic of fifteen-phase power transmission system. The power transmission system consists of a $765 \mathrm{kV}$, $50 \mathrm{~Hz}, 200 \mathrm{~km}$ long fifteen-phase transmission line which is divided into two zones. Each zone has a length of $100 \mathrm{~km}$. The fifteen-phase transmission line is fed from a $765 \mathrm{kV}$ source at the sending end and connected to a load at the receiving end. The model of fifteen-phase transmission line is developed and simulated for different types of faults using the simscape power system toolbox of MATLAB.

As shown in Figure 1, the current measurement blocks for the relay are connected at bus-1 to protect the entire length of fifteenphase transmission line.

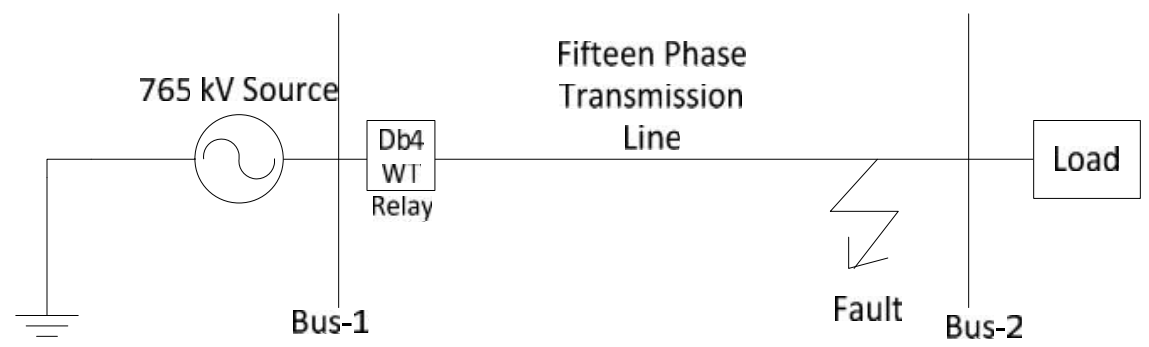

Figure 1. The schematic of fifteen-phase transmission line

\section{Db4 Wavelet Transform Based Protection Technique}

The daubechies-4 wavelet transform is formulated as:

$$
\mathrm{W}(\mathrm{j}, \mathrm{k})=\sum_{\mathrm{j}} \sum_{\mathrm{k}} \mathrm{x}(\mathrm{k}) 2^{-\mathrm{j} / 2} \varphi\left(2^{-\mathrm{j}} \mathrm{n}-\mathrm{k}\right)
$$

where a mother wavelet is designated as $\varphi(t)$ having finite energy.

High pass filter gain after sub-sampling twice is defined as:

Low pass filter gain after sub-sampling twice is defined as:

$$
\mathrm{y}_{\mathrm{H}}(\mathrm{k})=\sum_{\mathrm{n}} \mathrm{x}(\mathrm{n}) \mathrm{g}(2 \mathrm{k}-\mathrm{n})
$$

$$
\mathrm{y}_{\mathrm{L}}(\mathrm{k})=\sum_{\mathrm{n}} \mathrm{x}(\mathrm{n}) \mathrm{h}(2 \mathrm{k}-\mathrm{n})
$$

Figure 2 shows the process of daubechies- 4 wavelet transform for fault detection and classification. The steps for the same are shown below.

Step 1 Simulate the model for different types of faults and generate the fifteen-phase fault current signals.

Step 2 Analyze the fifteen-phase currents using daubechies-4 wavelet transform for the removal of their characteristics.

Step 3 Calculate the amplitudes of Db4WT coefficients for each fault current signal.

Step 4 The phase will be declared as the faulted phase if its Db4WT coefficient has the larger amplitude in comparison with the healthy phase. 


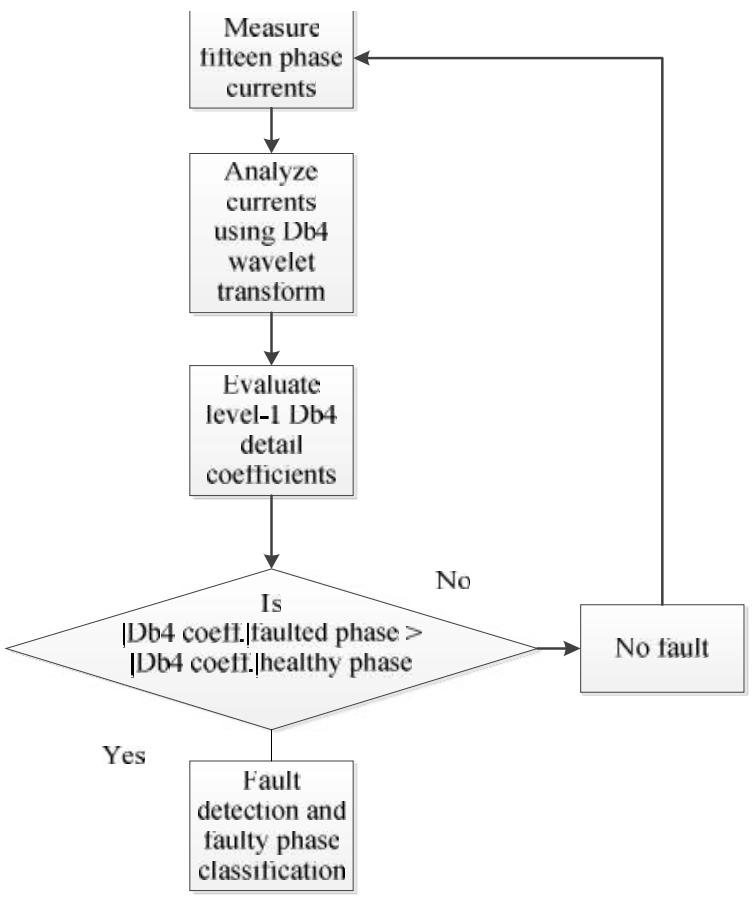

Figure 2. The schematic of fault detection technique using Db4 wavelet transform

\section{Results and Discussion}

The effectiveness of Db4 wavelet transform has been checked for various types of fault cases. The fault factors of the simulation model are varied in each case. The results are shown in the subsequent subsections.

4.1 Response for No-Fault: The Db4 wavelet transform is tested for no-fault condition. Figure 3 shows the fifteen-phase current for no fault. Figure 4 depicts the Db4 coefficients for no-fault. Table 1 reports the amplitudes of Db4 coefficients of fifteen-phase current for no-fault condition. It can be observed from Table 1 that the Db4 coefficients of all the phases have approximately same amplitudes for no-fault condition. The Db4 coefficients are also below the line of threshold. This verifies that the fifteen-phase transmission line has no-fault.

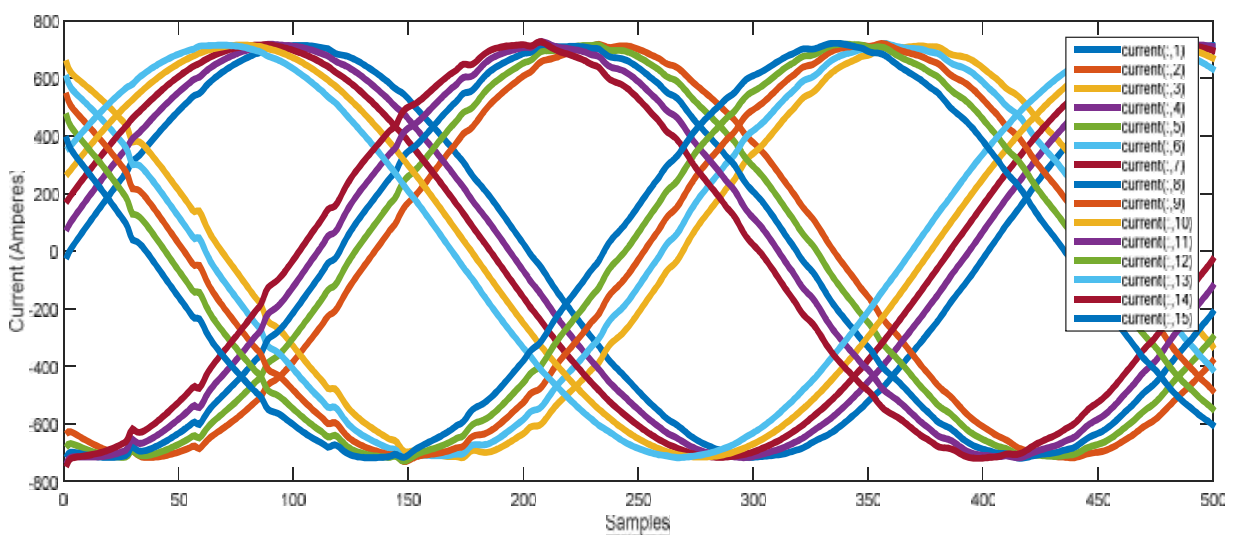

Figure 3. Diagram showing fifteen phase current for no-fault 


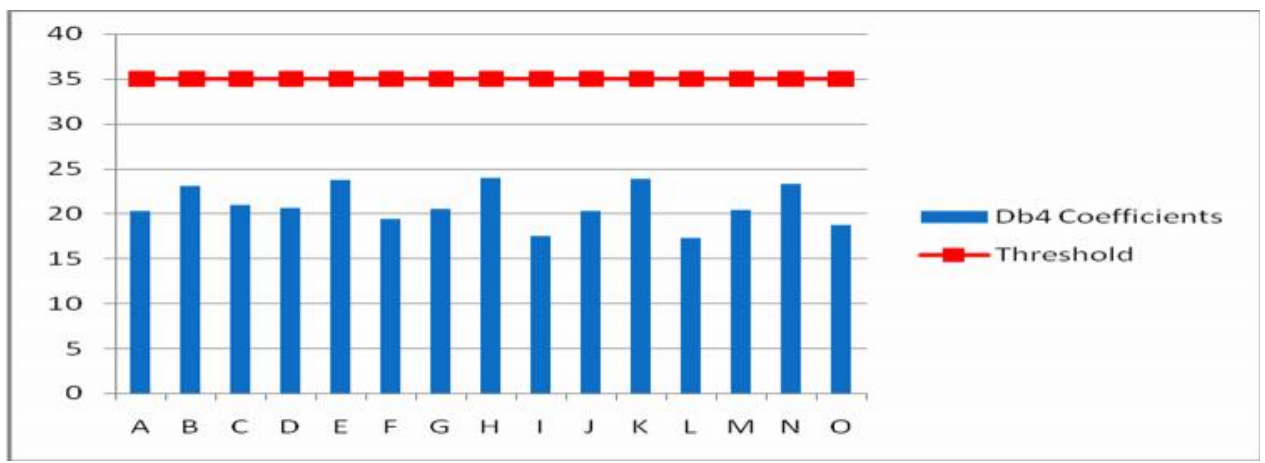

Figure 4. Db4 coefficients for no-fault

Table 1. Response of Db4WT for no-fault

\begin{tabular}{|c|c|c|c|c|c|}
\hline Phase & Db4 Coefficients & Phase & Db4 Coefficients & Phase & Db4 Coefficients \\
\hline A & 20.2428 & F & 19.3585 & K & 23.8020 \\
\hline B & 23.0169 & G & 20.5351 & L & 17.2858 \\
\hline C & 20.9093 & H & 23.9486 & M & 20.3973 \\
\hline D & 20.5649 & I & 17.4766 & N & 23.2481 \\
\hline E & 23.6854 & J & 20.3316 & O & 18.7622 \\
\hline
\end{tabular}

4.2 Response in Case of Wind Farm Integrated Fifteen-Phase Transmission Line: The performance of the proposed technique has been explored for the wind farm integrated fifteen-phase transmission line for the ten phase fault. Figure 5 shows the fifteen-phase current for 'BCFGHIJKLM-g' ten phase fault. Figure 6 illustrates the Db4 coefficients for 'BCFGHIJKLM-g' fault. Table 2 depicts the response of Db4WT for 'BCFGHIJKLM-g' ten phase fault at $65 \%$ from bus -1 at FIT $=0.2$ seconds with $\mathrm{R}_{\mathrm{f}}=\mathrm{R}_{\mathrm{g}}=15$

. From Table 2, it can be seen that the amplitudes of Db4WT coefficients of faulted phases 'BCFGHIJKLM' are larger than the amplitudes of Db4WT coefficients of the un-faulted phases and this shows that the proposed fault detection technique correctly detects and identifies the ten phase fault which is triggered on the wind farm connected fifteen phase transmission line.

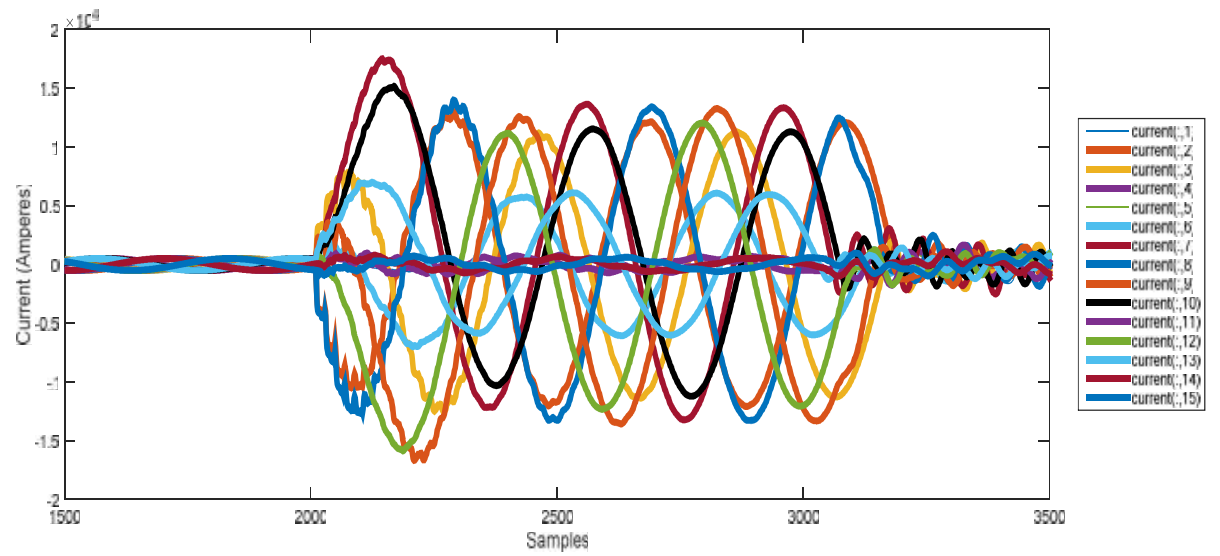

Figure 5. Fifteen phase current for 'BCFGHIJKLM-g' fault at $65 \%$ from bus-1 at FIT $=0.2$ seconds with $R_{f}=R_{g}=15$

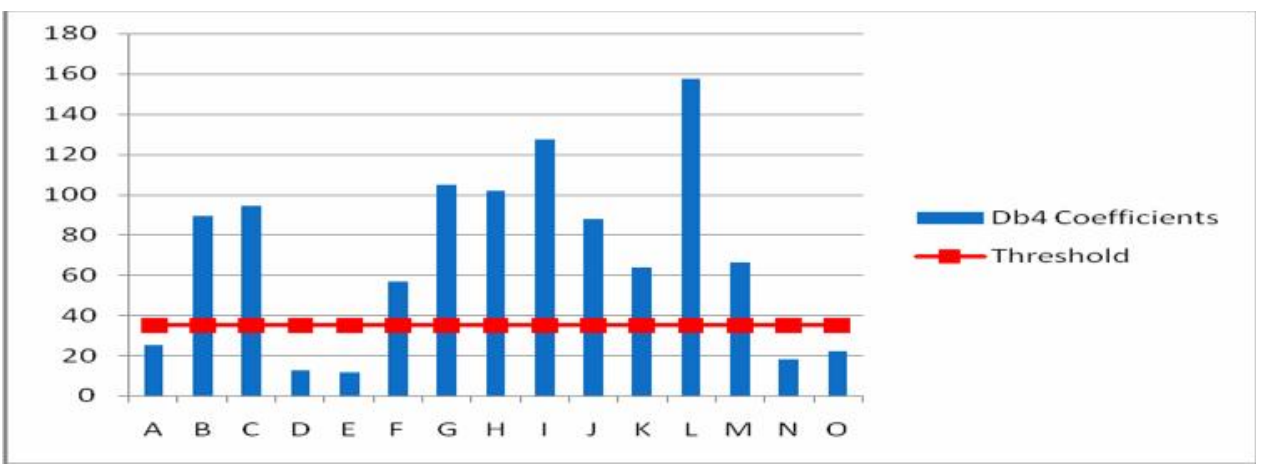

Figure 6. Db4 coefficients for 'BCFGHIJKLM-g' fault at $65 \%$ from bus-1 
Table 2. Response of Db4WT for 'BCFGHIJKLM-g' fault at $65 \%$ from bus-1 at FIT $=0.2$ seconds with $\mathrm{R}_{\mathrm{f}}=\mathrm{R}_{\mathrm{g}}=15$

\begin{tabular}{|c|c|c|c|c|c|}
\hline Phase & Db4 Coefficients & Phase & Db4 Coefficients & Phase & Db4 Coefficients \\
\hline A & 24.8194 & F & $\mathbf{5 6 . 5 6 9 6}$ & K & $\mathbf{6 3 . 8 0 0 5}$ \\
\hline B & $\mathbf{8 9 . 4 6 5 4}$ & G & $\mathbf{1 0 5 . 0 4 0 7}$ & L & $\mathbf{1 5 7 . 3 4 3 1}$ \\
\hline C & $\mathbf{9 4 . 2 1 8 7}$ & H & $\mathbf{1 0 1 . 9 0 2 4}$ & M & $\mathbf{6 6 . 2 0 4 2}$ \\
\hline D & 12.3217 & I & $\mathbf{1 2 7 . 1 1 2 6}$ & N & 18.0093 \\
\hline E & 11.7320 & J & $\mathbf{8 7 . 5 9 5 6}$ & O & 21.9660 \\
\hline
\end{tabular}

4.3 Response in Case of Inter-Circuit Fault: The simulation study has been conducted to examine the performance of the proposed technique for the inter-circuit fault. Figure 7 depicts the Db4 coefficients for 'AEIKO-g' five phase to ground inter-circuit fault. The result of wavelet transform for 'AEIKO-g' inter-circuit fault simulated at $45 \%$ from bus- 1 at FIT $=0.35$ seconds with $R_{f}=R_{g}=$ 0.001 is reported in Table 3. From Table 3, it can be seen that the amplitudes of Db4WT coefficients of the faulted phases are greater than the amplitudes of Db4WT coefficients of the un-faulted phases which shows that the proposed scheme correctly detects and identifies the inter-circuit fault.

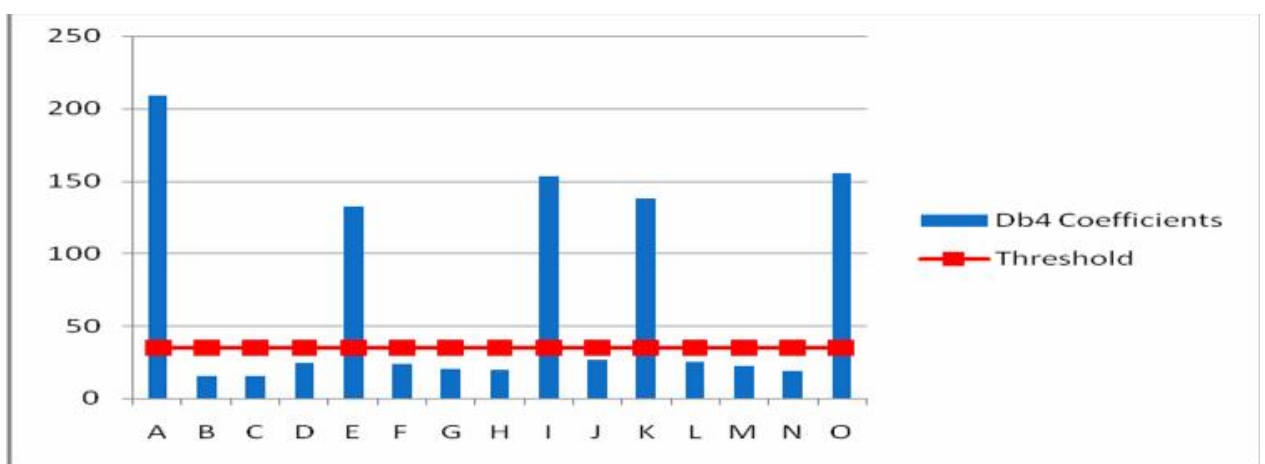

Figure 7. Db4 coefficients for 'AEIKO-g' inter-circuit fault at 45\% from bus-1

Table 3. Response of Db4WT for 'AEIKO-g' inter-circuit fault at $45 \%$ from bus- 1 at FIT $=0.35$ seconds with $R_{f}=R_{g}=0.001$

\begin{tabular}{|c|c|c|c|c|c|}
\hline Phase & Db4 Coefficients & Phase & Db4 Coefficients & Phase & Db4 Coefficients \\
\hline A & $\mathbf{2 0 8 . 5 6 6 3}$ & F & 23.3426 & K & $\mathbf{1 3 8 . 1 5 8 2}$ \\
\hline B & 15.5591 & G & 20.3954 & L & 25.2641 \\
\hline C & 15.2882 & H & 19.3108 & M & 22.2071 \\
\hline D & 24.3561 & I & $\mathbf{1 5 3 . 4 3 9 4}$ & N & 18.6097 \\
\hline E & $\mathbf{1 3 2 . 3 9 3 5}$ & J & 26.2368 & $\mathbf{O}$ & $\mathbf{1 5 4 . 9 5 7 4}$ \\
\hline
\end{tabular}

4.4 Response in Case of Fault Resistance Variation: The Db4 wavelet transform has been investigated for variation in fault resistance. The fault resistances are varied from 0.5 to 145 . All the faults were simulated at a distance of $50 \%$ from bus- 1 . Figures 8-12 shows the Db4 coefficients for different faults with different fault resistances. The results of Db4WT for fault resistance variation are reported in Tables 4-8. It is examined from Tables 4-8 that all the faults have been correctly detected and the faulty phases have been correctly identified with the help of Db4 wavelet transform.

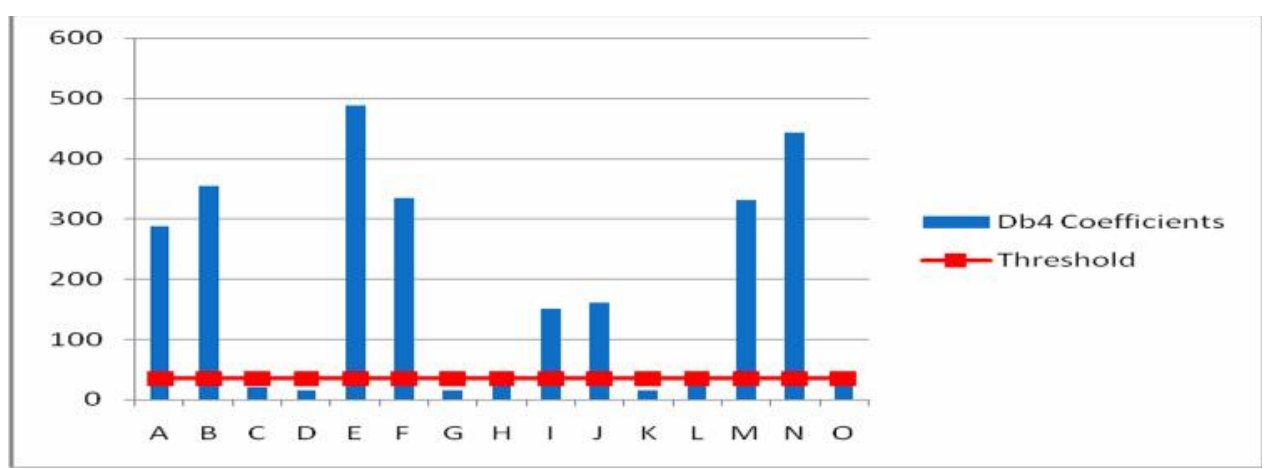

Figure 8. $\mathrm{Db} 4$ coefficients for 'ABEFIJMN-g' fault at $50 \%$ from bus- 1 with $\mathrm{R}_{\mathrm{f}}=0.5$ 
Table 4. Response of Db4WT for 'ABEFIJMN-g' fault with $\mathrm{R}_{\mathrm{f}}=0.5, \mathrm{R}_{\mathrm{g}}=0.001 \quad$, FIT $=0.1$ seconds and $\mathrm{F}_{1}=50 \%$

\begin{tabular}{|c|c|c|c|c|c|}
\hline Phase & Db4 Coefficients & Phase & Db4 Coefficients & Phase & Db4 Coefficients \\
\hline $\mathbf{A}$ & 287.8500 & $\mathbf{F}$ & 334.3511 & $\mathbf{K}$ & 14.5572 \\
\hline B & 354.3502 & $\mathbf{G}$ & 15.8225 & $\mathbf{L}$ & 23.6324 \\
\hline $\mathbf{C}$ & 20.2261 & $\mathbf{H}$ & 21.6168 & $\mathbf{M}$ & 330.4511 \\
\hline D & 14.7688 & I & 150.3564 & $\mathbf{N}$ & 442.2578 \\
\hline $\mathbf{E}$ & 487.7033 & $\mathbf{J}$ & 159.8848 & $\mathbf{O}$ & 21.6074 \\
\hline
\end{tabular}

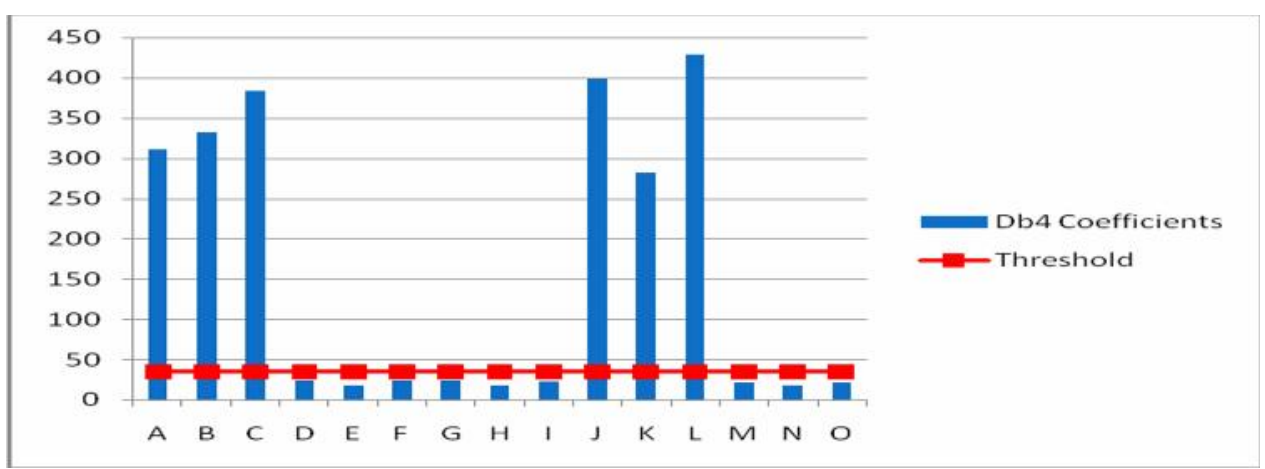

Figure 9. Db4 coefficients for 'ABCJKL-g' fault at 50\% from bus-1 with $\mathrm{R}_{\mathrm{f}}=25$

Table 5. Response of Db4WT for 'ABCJKL-g' fault with $\mathrm{R}_{\mathrm{f}}=25, \mathrm{R}_{\mathrm{g}}=0.001, \mathrm{FIT}=0.3$ seconds and $\mathrm{F}_{1}=50 \%$

\begin{tabular}{|c|c|c|c|c|c|}
\hline Phase & Db4 Coefficients & Phase & Db4 Coefficients & Phase & Db4 Coefficients \\
\hline A & $\mathbf{3 1 0 . 9 2 8 2}$ & F & 23.3692 & K & L \\
\hline B & $\mathbf{3 3 2 . 6 4 3 3}$ & G & 23.2525 & M & 428.2299 \\
\hline C & $\mathbf{3 8 3 . 3 4 2 5}$ & H & 18.0868 & N & 17.6253 \\
\hline D & 23.4746 & I & 22.8626 & $\mathbf{O}$ & 21.7084 \\
\hline
\end{tabular}

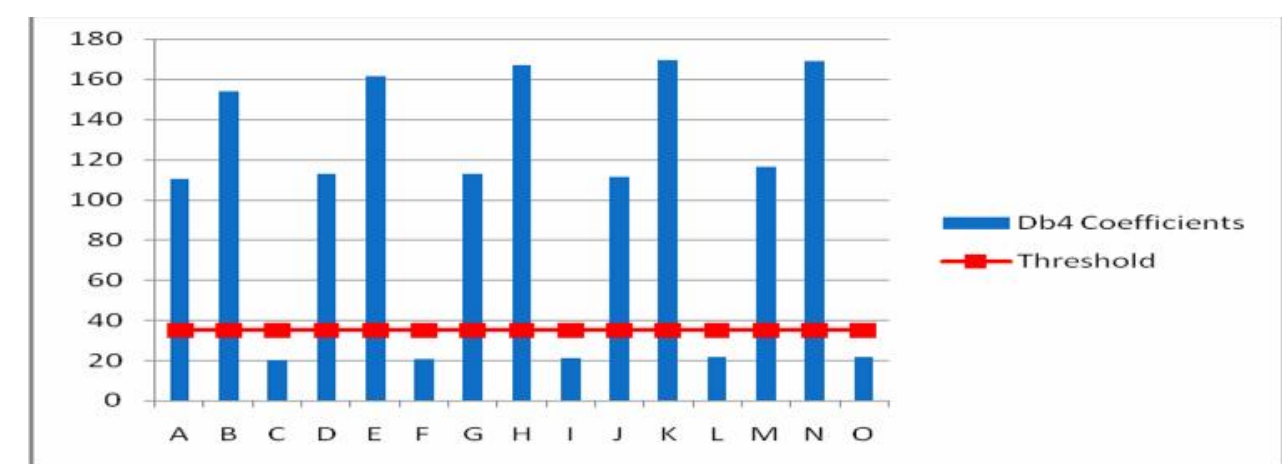

Figure 10. Db4 coefficients for 'ABDEGHJKMN-g' fault at $50 \%$ from bus-1 with $\mathrm{R}_{\mathrm{f}}=65$

Table 6. Response of Db4WT for 'ABDEGHJKMN-g' fault with $\mathrm{R}_{\mathrm{f}}=65, \mathrm{R}_{\mathrm{g}}=0.001 \quad$, FIT $=0.4$ seconds and $\mathrm{F}_{1}=50 \%$

\begin{tabular}{|c|c|c|c|c|c|}
\hline Phase & Db4 Coefficients & Phase & Db4 Coefficients & Phase & Db4 Coefficients \\
\hline A & $\mathbf{1 1 0 . 2 9 7 3}$ & F & 20.5578 & K & L \\
\hline B & $\mathbf{1 5 3 . 6 9 0 0}$ & G & $\mathbf{1 1 2 . 9 7 3 7}$ & 21.6245 \\
\hline C & 20.2074 & H & $\mathbf{1 6 6 . 9 0 1 4}$ & M & N \\
\hline D & $\mathbf{1 1 2 . 5 9 8 8}$ & I & 21.2460 & $\mathbf{1 1 6 . 5 5 8 3}$ \\
\hline E & $\mathbf{1 6 1 . 6 7 8 9}$ & J & $\mathbf{1 1 1 . 4 1 5 6}$ & $\mathbf{O}$ & \\
\hline
\end{tabular}




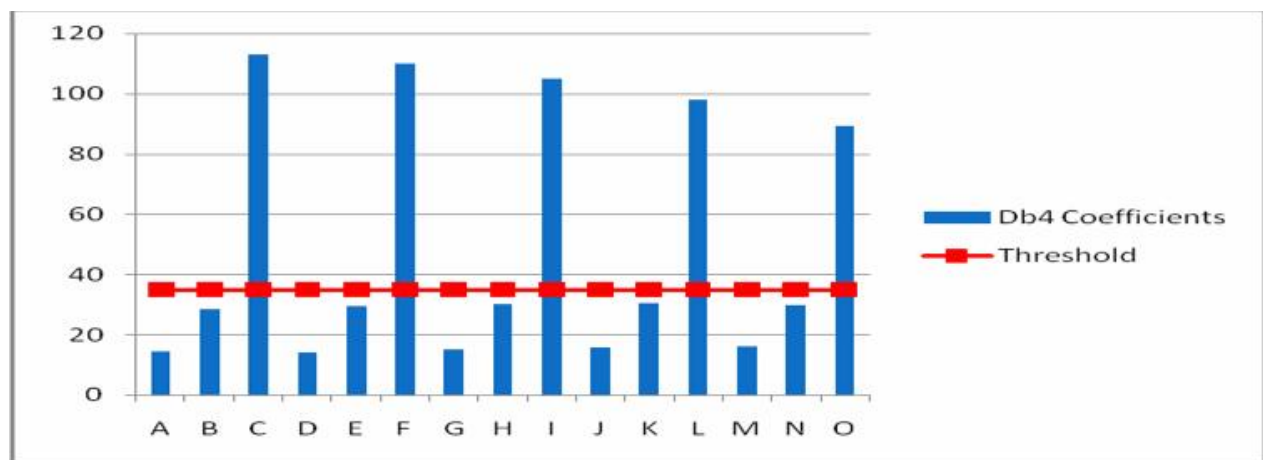

Figure 11. Db4 coefficients for 'CFILO-g' fault at $50 \%$ from bus- 1 with $\mathrm{R}_{\mathrm{f}}=105$

Table 7. Response of Db4WT for 'CFILO-g' fault with $\mathrm{R}_{\mathrm{f}}=105 \quad, \mathrm{R}_{\mathrm{g}}=0.001 \quad$, FIT $=0.1$ seconds and $\mathrm{F}_{1}=50 \%$

\begin{tabular}{|c|c|c|c|c|c|}
\hline Phase & Db4 Coefficients & Phase & Db4 Coefficients & Phase & Db4 Coefficients \\
\hline A & 14.5230 & F & $\mathbf{1 0 9 . 9 0 1 7}$ & K & 30.2519 \\
\hline B & 28.2698 & G & 14.8870 & L & $\mathbf{9 7 . 9 2 8 5}$ \\
\hline C & $\mathbf{1 1 3 . 1 1 1 2}$ & H & 30.1024 & M & 16.0306 \\
\hline D & 13.9271 & I & $\mathbf{1 0 4 . 8 1 1 8}$ & N & 29.8837 \\
\hline E & 29.4379 & J & 15.5922 & O & $\mathbf{8 9 . 3 6 9 6}$ \\
\hline
\end{tabular}

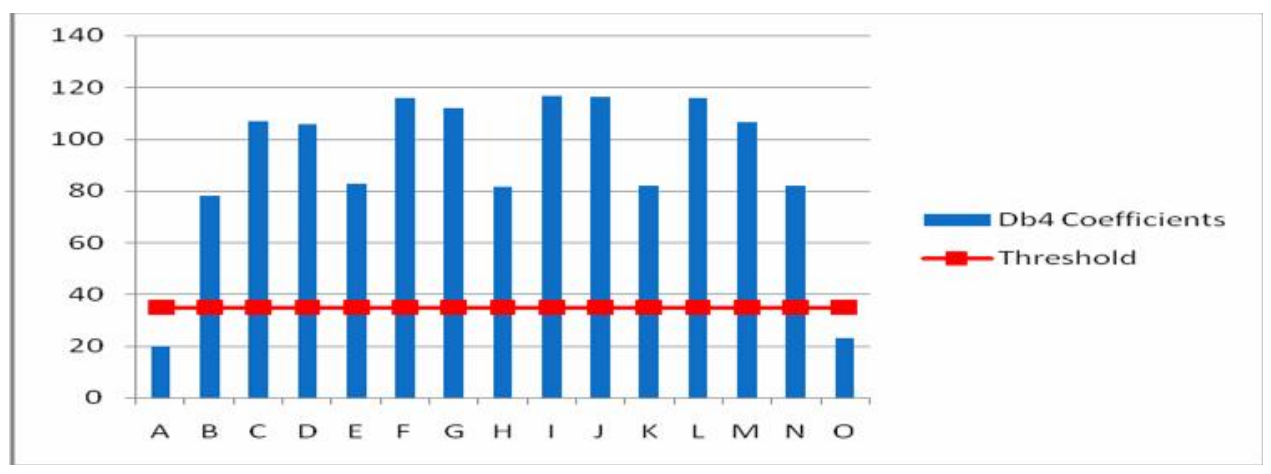

Figure 12. Db4 coefficients for 'BCDEFGHIJKLMN-g' fault at $50 \%$ from bus- 1 with $\mathrm{R}_{\mathrm{f}}=145$

Table 8. Response of Db4WT for 'BCDEFGHIJKLMN-g' fault with $R_{f}=145 \quad, R_{g}=0.001 \quad$, FIT $=0.25$ seconds and $F_{1}=50 \%$

\begin{tabular}{|c|c|c|c|c|c|}
\hline Phase & Db4 Coefficients & Phase & Db4 Coefficients & Phase & Db4 Coefficients \\
\hline A & 19.8395 & F & $\mathbf{1 1 5 . 6 3 9 8}$ & K & $\mathbf{8 1 . 9 0 7 6}$ \\
\hline B & $\mathbf{7 7 . 9 9 4 0}$ & G & $\mathbf{1 1 1 . 9 8 7 0}$ & L & $\mathbf{1 1 5 . 8 3 9 5}$ \\
\hline C & $\mathbf{1 0 6 . 9 1 7 2}$ & H & $\mathbf{8 1 . 6 7 2 5}$ & M & $\mathbf{1 0 6 . 4 7 0 3}$ \\
\hline D & $\mathbf{1 0 5 . 7 2 9 8}$ & I & $\mathbf{1 1 6 . 7 3 8 3}$ & N & $\mathbf{8 1 . 7 0 2 1}$ \\
\hline E & $\mathbf{8 2 . 4 8 4 3}$ & J & $\mathbf{1 1 6 . 3 2 8 0}$ & $\mathbf{O}$ & 22.9223 \\
\hline
\end{tabular}

4.5 Response in Case of Ground Resistance Variation: The Db4 wavelet transform has been explored for variation in ground resistance. The ground resistances are varied from 5 to 155 . All the faults were simulated at a distance of $50 \%$ from bus-1. Figures 13-17 exemplifies the Db4 coefficients for different faults with different ground resistances. Tables 9-13 report the results of Db4WT for different ground resistances. From Tables 9-13, it can be observed that the performance of the Db4 wavelet transform is not affected by ground resistance variation. 


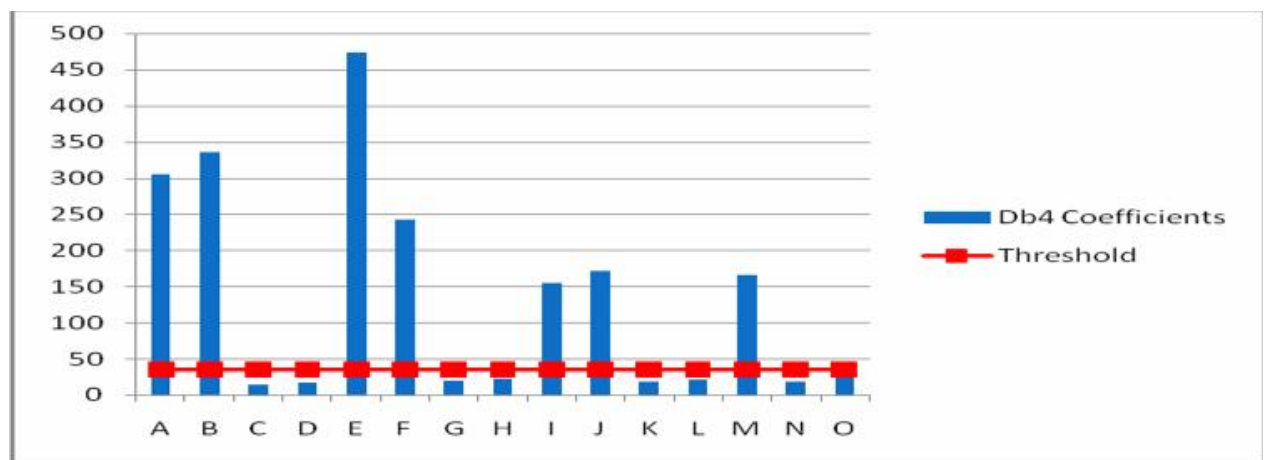

Figure 13. Db4 coefficients for 'ABEFIJM-g' fault at $50 \%$ from bus- 1 with $\mathrm{R}_{\mathrm{g}}=5$

Table 9. Response of Db4WT for 'ABEFIJM-g' fault with $\mathrm{R}_{\mathrm{g}}=5 \quad, \mathrm{R}_{\mathrm{f}}=0.001 \quad$, FIT $=0.1$ seconds and $\mathrm{F}_{1}=50 \%$

\begin{tabular}{|c|c|c|c|c|c|}
\hline Phase & Db4 Coefficients & Phase & Db4 Coefficients & Phase & Db4 Coefficients \\
\hline A & $\mathbf{3 0 5 . 1 0 6 6}$ & F & $\mathbf{2 4 2 . 3 2 7 7}$ & K & 18.0085 \\
\hline B & $\mathbf{3 3 5 . 7 1 9 4}$ & G & 19.6527 & L & 20.4323 \\
\hline C & 13.4456 & H & 22.2776 & M & $\mathbf{1 6 5 . 2 6 0 1}$ \\
\hline D & 17.1818 & I & $\mathbf{1 5 4 . 3 0 5 6}$ & N & 18.0175 \\
\hline E & $\mathbf{4 7 2 . 9 1 7 6}$ & J & $\mathbf{1 7 0 . 8 8 3 4}$ & O & 23.2581 \\
\hline
\end{tabular}

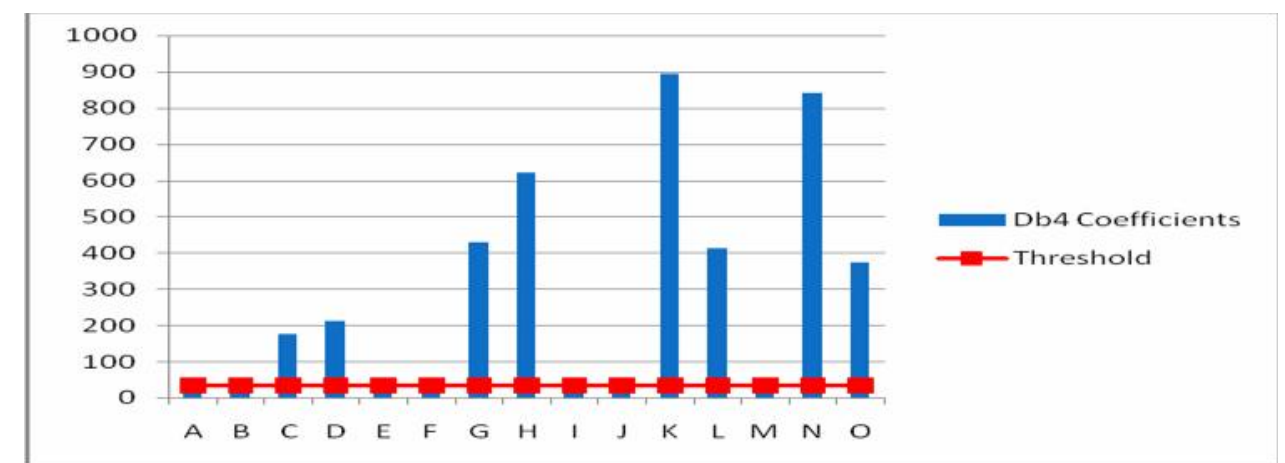

Figure 14. Db4 coefficients for 'CDGHKLNO-g' fault at $50 \%$ from bus-1 with $\mathrm{R}_{\mathrm{g}}=35$

Table 10. Response of Db4WT for 'CDGHKLNO-g' fault with $\mathrm{R}_{\mathrm{g}}=35, \mathrm{R}_{\mathrm{f}}=0.001 \quad$, FIT $=0.1$ seconds and $\mathrm{F}_{1}=50 \%$

\begin{tabular}{|c|c|c|c|c|c|}
\hline Phase & Db4 Coefficients & Phase & Db4 Coefficients & Phase & Db4 Coefficients \\
\hline A & 21.2112 & F & 40.0141 & K & $\mathbf{8 9 3 . 7 7 0 3}$ \\
\hline B & 39.5643 & G & $\mathbf{4 2 9 . 8 6 2 5}$ & L & $\mathbf{4 1 2 . 1 7 1 5}$ \\
\hline C & $\mathbf{1 7 4 . 6 2 9 9}$ & H & $\mathbf{6 2 1 . 9 9 2 8}$ & M & 30.7047 \\
\hline D & $\mathbf{2 1 2 . 5 6 4 6}$ & I & 20.3387 & N & $\mathbf{8 4 2 . 5 9 1 5}$ \\
\hline E & 24.0427 & J & 31.2305 & $\mathbf{O}$ & $\mathbf{3 7 3 . 1 3 8 2}$ \\
\hline
\end{tabular}

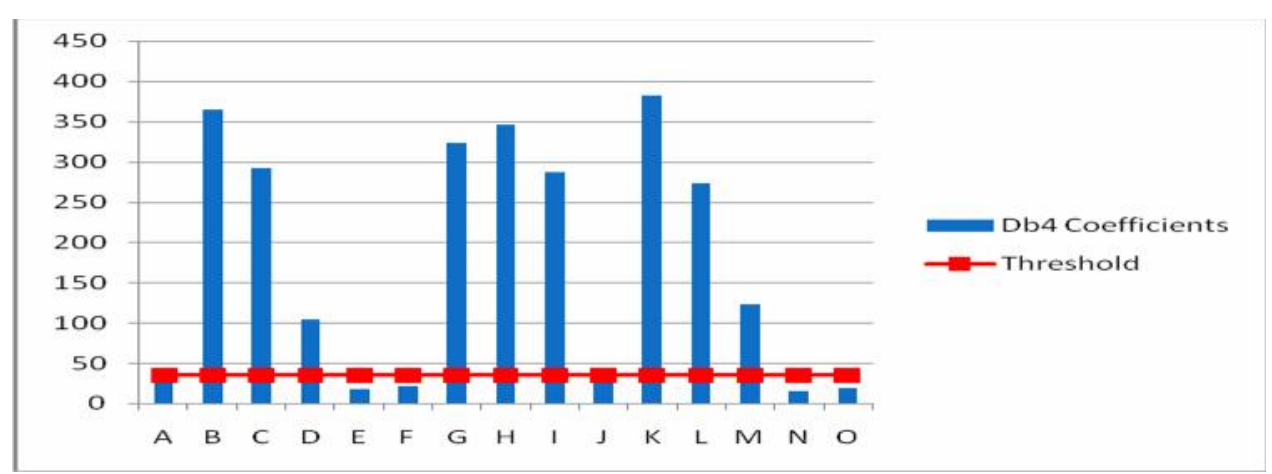

Figure 15. Db4 coefficients for 'BCDGHIKLM-g' fault at $50 \%$ from bus- 1 with $R_{g}=75$ 
Table 11. Response of Db4WT for 'BCDGHIKLM-g' fault with $\mathrm{R}_{\mathrm{g}}=75, \mathrm{R}_{\mathrm{f}}=0.001 \quad$, FIT $=0.1$ seconds and $\mathrm{F}_{1}=50 \%$

\begin{tabular}{|c|c|c|c|c|c|}
\hline Phase & Db4 Coefficients & Phase & Db4 Coefficients & Phase & Db4 Coefficients \\
\hline A & 25.7099 & F & 21.1927 & K & $\mathbf{3 8 2 . 2 4 4 3}$ \\
\hline B & $\mathbf{3 6 4 . 6 0 5 8}$ & G & $\mathbf{3 2 3 . 3 7 5 5}$ & L & $\mathbf{2 7 3 . 3 6 5 4}$ \\
\hline C & $\mathbf{2 9 2 . 1 0 0 9}$ & H & $\mathbf{3 4 5 . 9 0 1 7}$ & M & $\mathbf{1 2 3 . 0 3 1 4}$ \\
\hline D & $\mathbf{1 0 3 . 7 8 4 8}$ & I & $\mathbf{2 8 7 . 0 6 0 8}$ & N & 15.1812 \\
\hline E & 17.1320 & J & 32.5759 & O & 18.6668 \\
\hline
\end{tabular}

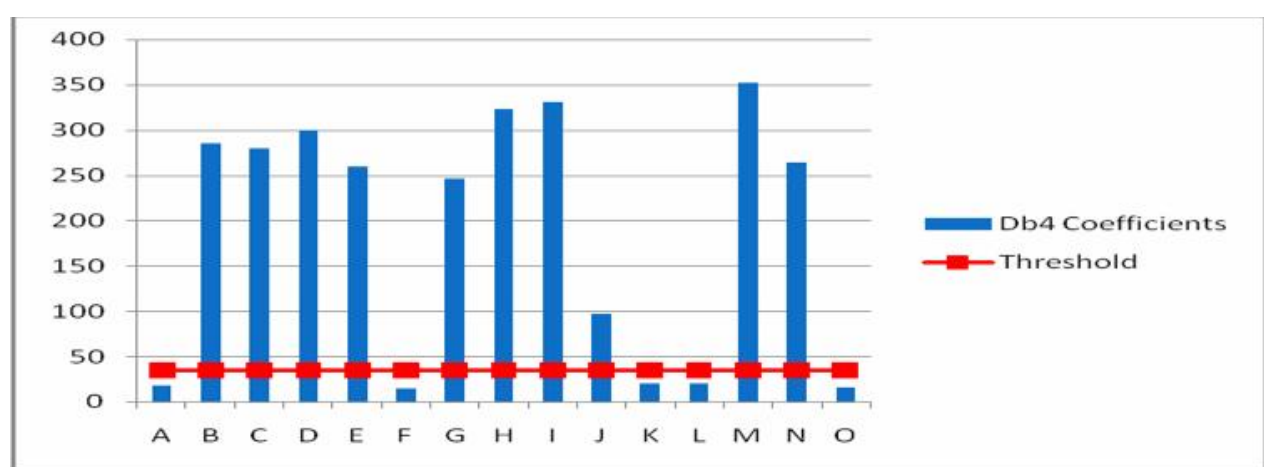

Figure 16. Db4 coefficients for 'BCDEGHIJMN-g' fault at 50\% from bus-1 with $\mathrm{R}_{\mathrm{g}}=115$

Table 12. Response of Db4WT for 'BCDEGHIJMN-g' fault with $\mathrm{R}_{\mathrm{g}}=115 \quad, \mathrm{R}_{\mathrm{f}}=0.001 \quad$, FIT $=0.1$ seconds, $\mathrm{F}_{1}=50 \%$

\begin{tabular}{|c|c|c|c|c|c|}
\hline Phase & Db4 Coefficients & Phase & Db4 Coefficients & Phase & Db4 Coefficients \\
\hline A & 17.6909 & F & 14.5911 & K & 19.5529 \\
\hline B & $\mathbf{2 8 5 . 3 8 5 4}$ & G & $\mathbf{2 4 6 . 6 6 0 4}$ & L & 19.9184 \\
\hline C & $\mathbf{2 7 9 . 9 1 3 7}$ & H & $\mathbf{3 2 3 . 6 6 4 2}$ & M & $\mathbf{3 5 1 . 9 0 1 4}$ \\
\hline D & $\mathbf{2 9 9 . 7 4 5 6}$ & I & $\mathbf{3 3 0 . 5 1 3 1}$ & N & $\mathbf{2 6 4 . 4 8 6 4}$ \\
\hline E & $\mathbf{2 5 9 . 1 9 7 2}$ & J & $\mathbf{9 6 . 7 8 4 9}$ & O & 16.0876 \\
\hline
\end{tabular}

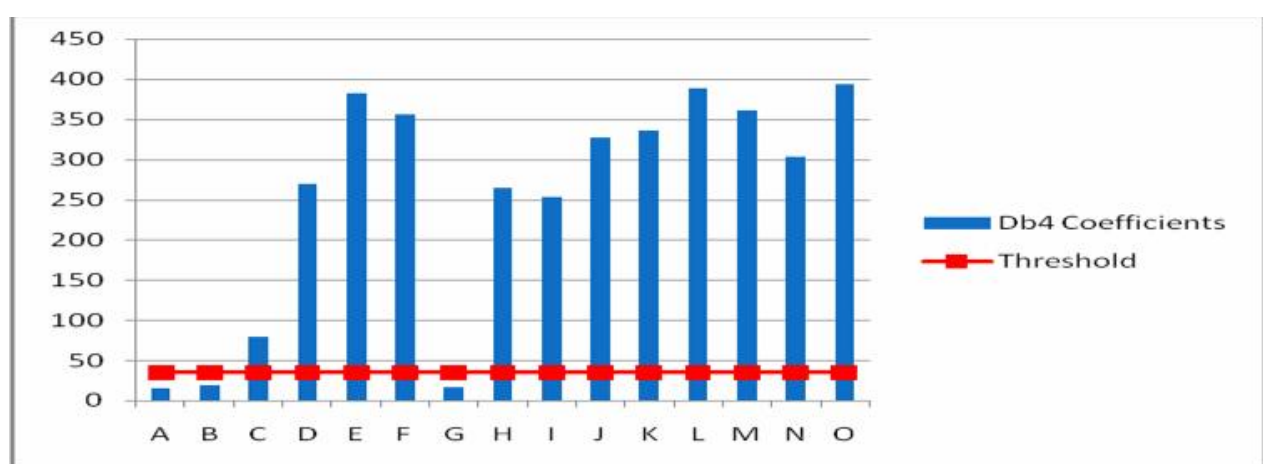

Figure 17. Db4 coefficients for 'CDEFHIJKLMNO-g' fault at 50\% from bus-1 with $\mathrm{R}_{\mathrm{g}}=155$

Table 13. Response of Db4WT for 'CDEFHIJKLMNO-g' fault with $\mathrm{R}_{\mathrm{g}}=155 \quad, \mathrm{R}_{\mathrm{f}}=0.001 \quad$, FIT $=0.1$ seconds, $\mathrm{F}_{1}=50 \%$

\begin{tabular}{|c|c|c|c|c|c|}
\hline Phase & Db4 Coefficients & Phase & Db4 Coefficients & Phase & Db4 Coefficients \\
\hline A & 14.8026 & F & $\mathbf{3 5 6 . 6 0 3 9}$ & K & $\mathbf{3 3 5 . 3 6 5 5}$ \\
\hline B & 18.9373 & G & 16.7689 & L & $\mathbf{3 8 7 . 9 8 5 6}$ \\
\hline C & $\mathbf{7 8 . 9 7 9 7}$ & H & $\mathbf{2 6 4 . 5 7 4 2}$ & M & $\mathbf{3 6 1 . 3 9 1 9}$ \\
\hline D & $\mathbf{2 6 9 . 1 1 4 4}$ & I & $\mathbf{2 5 2 . 6 7 4 6}$ & N & $\mathbf{3 0 2 . 8 0 3 6}$ \\
\hline E & $\mathbf{3 8 2 . 8 1 5 6}$ & J & $\mathbf{3 2 7 . 6 9 8 4}$ & O & $\mathbf{3 9 3 . 8 2 5 5}$ \\
\hline
\end{tabular}


4.6 Response in Case of Multi-Position Faults: The Db4 wavelet transform has been tested for the multi-position faults. Tables 1418 report the results for various multi-position faults. Figures 18-22 exemplifies the Db4 coefficients for various multi-position faults simulated at different locations. The fault factors are varied in each fault case. From Tables 14-18, it can be examined that the $\mathrm{Db} 4$ wavelet transform effectively detects the multi-position faults.

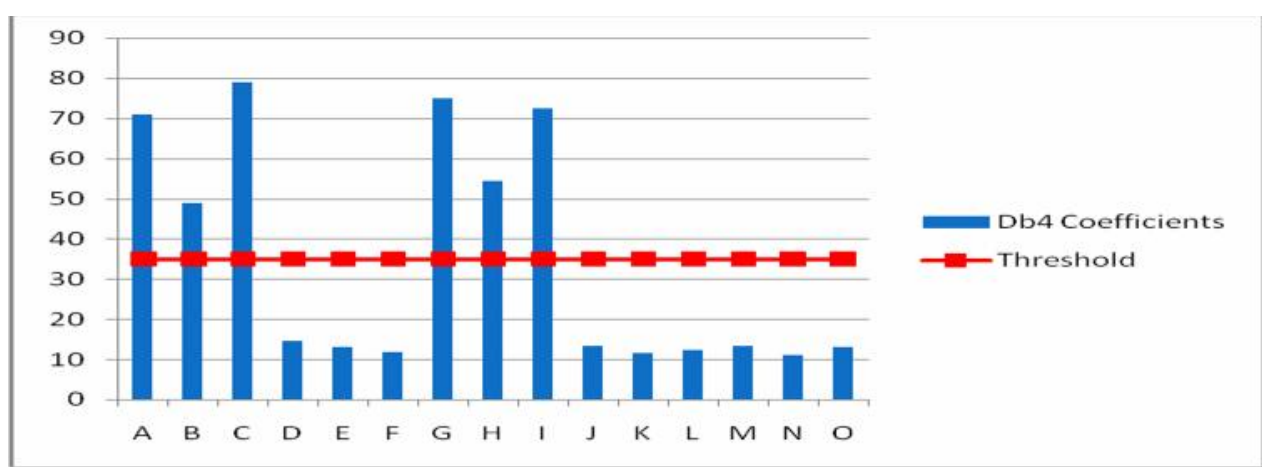

Figure 18. Db4 coefficients for 'ABC-g' fault at $40 \%$ and 'GHI-g' fault at $25 \%$ from bus-1

Table 14. Response of Db4WT for 'ABC-g' fault at $40 \%$ and 'GHI-g' fault at $25 \%$ from bus-1 with $\mathrm{R}_{\mathrm{f}}=\mathrm{R}_{\mathrm{g}}=150$ and FIT $=0.1$

\begin{tabular}{|c|c|c|c|c|c|}
\hline Phase & Db4 Coefficients & Phase & Db4 Coefficients & Phase & Db4 Coefficients \\
\hline A & $\mathbf{7 1 . 0 5 0 9}$ & F & 11.8240 & K & 11.4851 \\
\hline B & $\mathbf{4 9 . 0 0 8 5}$ & G & $\mathbf{7 4 . 8 6 6 8}$ & L & 12.3672 \\
\hline C & $\mathbf{7 9 . 0 0 3 1}$ & H & $\mathbf{5 4 . 3 2 2 7}$ & M & 13.1755 \\
\hline D & 14.6216 & I & $\mathbf{7 2 . 3 9 1 0}$ & N & 11.0796 \\
\hline E & 13.0946 & J & 13.2363 & O & 12.9632 \\
\hline
\end{tabular}

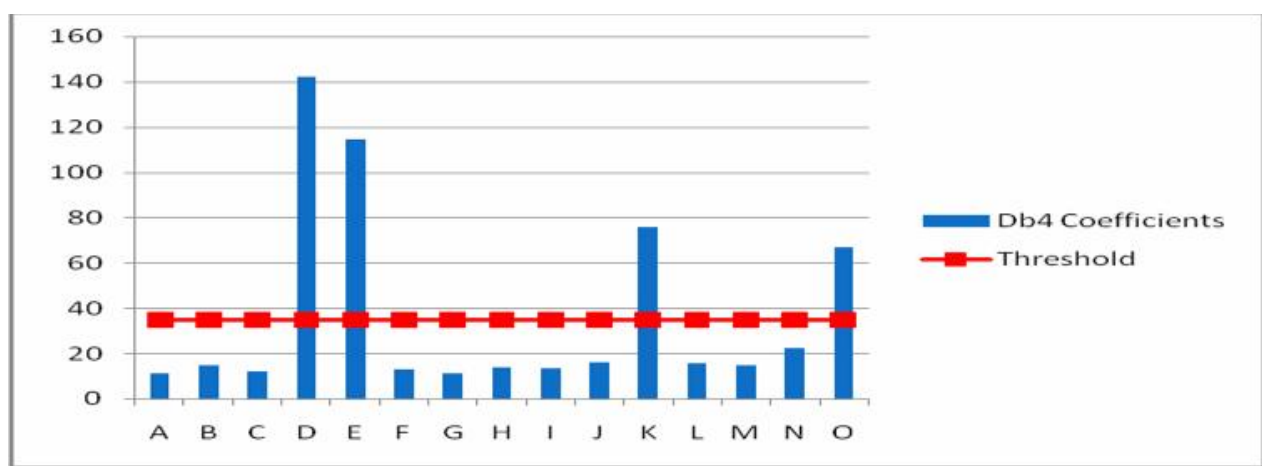

Figure 19. Db4 coefficients for 'DE-g' fault at $50 \%$, 'K-g' fault at $35 \%$ and 'O-g' fault at $15 \%$ from bus-1

Table 15. Response of Db4WT for 'DE-g' fault at 50\%, 'K-g' fault at 35\% and 'O-g' fault at $15 \%$ from bus-1 with $\mathrm{R}_{\mathrm{f}}=\mathrm{R}_{\mathrm{g}}=50$ and FIT $=0.3$ seconds

\begin{tabular}{|c|c|c|c|c|c|}
\hline Phase & Db4 Coefficients & Phase & Db4 Coefficients & Phase & Db4 Coefficients \\
\hline A & 11.1320 & F & 12.8357 & K & $\mathbf{7 5 . 6 8 3 2}$ \\
\hline B & 14.6882 & G & 11.0507 & L & 15.4747 \\
\hline C & 11.9255 & H & 13.7271 & M & 14.5367 \\
\hline D & $\mathbf{1 4 2 . 2 0 7 7}$ & I & 13.5320 & N & 22.3039 \\
\hline E & $\mathbf{1 1 4 . 7 3 9 1}$ & J & 16.0629 & $\mathbf{O}$ & $\mathbf{6 6 . 9 3 1 5}$ \\
\hline
\end{tabular}




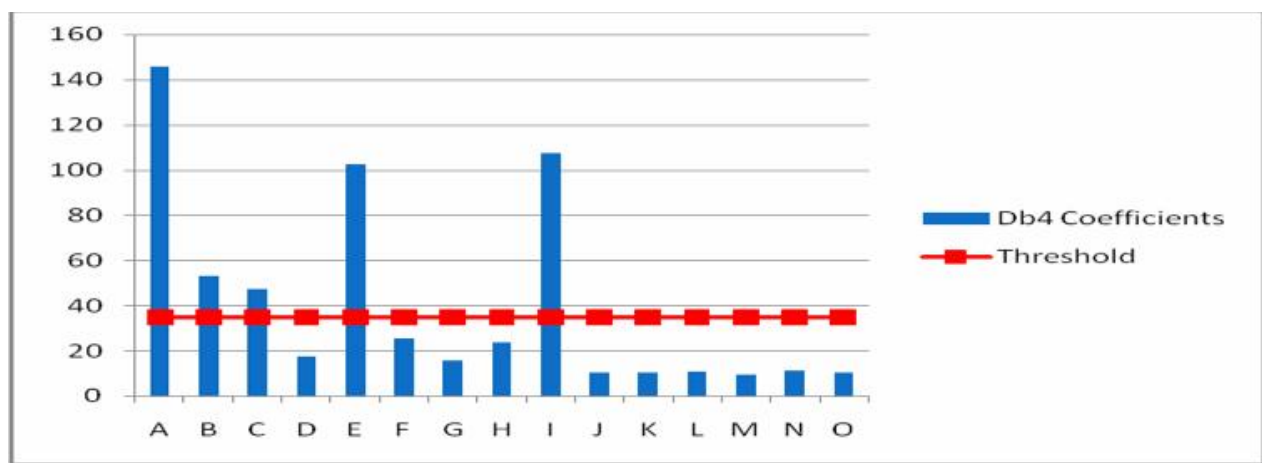

Figure 20. Db4 coefficients for 'ABC-g' fault at $7.5 \%$, 'E-g' fault at $10 \%$ and ' $\mathrm{I}-\mathrm{g}$ ' fault at $12.5 \%$ from bus-1

Table 16. Response of Db4WT for 'A-g' fault at 7.5\%, 'E-g' fault at $10 \%$ and 'I-g' fault at $12.5 \%$ from bus-1 with $\mathrm{R}_{\mathrm{f}}=\mathrm{R}_{\mathrm{g}}=25$

\begin{tabular}{|c|c|c|c|c|c|}
\hline \multicolumn{7}{|c|}{ and FIT $=0.25$ seconds } & Phase & Db4 Coefficients \\
\hline Phase & Db4 Coefficients & Phase & Db4 Coefficients & K & 10.2070 \\
\hline A & $\mathbf{1 4 5 . 9 2 9 0}$ & F & 25.2851 & L & 10.4928 \\
\hline B & $\mathbf{5 2 . 9 3 9 8}$ & G & 15.6830 & M & 9.4410 \\
\hline C & $\mathbf{4 7 . 3 6 5 2}$ & H & 23.8180 & N & 11.0584 \\
\hline D & 17.5109 & I & $\mathbf{1 0 7 . 4 8 5 5}$ & O & 10.2398 \\
\hline E & $\mathbf{1 0 2 . 6 6 0 4}$ & J & 10.3579 & \\
\hline
\end{tabular}

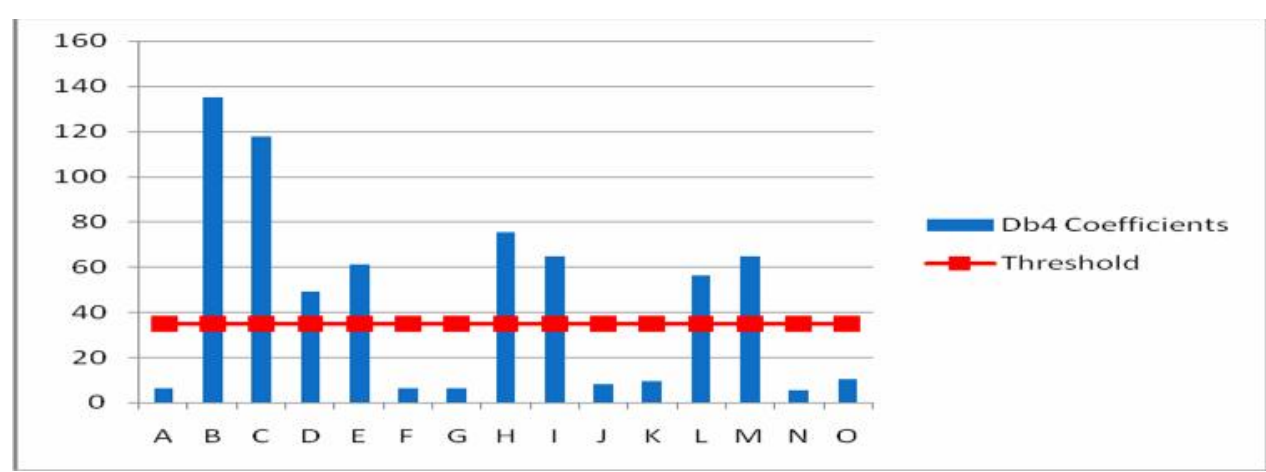

Figure 21. Db4 coefficient for 'BC-g' fault at 20\%, 'DE-g' fault at 90\%, 'HI-g' fault at 50\% and 'LM-g' fault at $100 \%$ from bus-1

Table 17. Response of Db4WT for 'BC-g' fault at 20\%, 'DE-g' fault at 90\%, 'HI-g' fault at $50 \%$ and 'LM-g' fault at $100 \%$ from bus- 1 with $\mathrm{R}_{\mathrm{f}}=\mathrm{R}_{\mathrm{g}}=10$ and FIT $=0.1$ seconds

\begin{tabular}{|c|c|c|c|c|c|}
\hline Phase & Db4 Coefficients & Phase & Db4 Coefficients & Phase & Db4 Coefficients \\
\hline A & 6.1796 & F & 6.3126 & K & 9.3510 \\
\hline B & $\mathbf{1 3 4 . 8 4 5 8}$ & G & 6.3327 & L & $\mathbf{5 6 . 0 5 9 8}$ \\
\hline C & $\mathbf{1 1 7 . 4 9 1 7}$ & H & $\mathbf{7 5 . 5 1 2 2}$ & M & $\mathbf{6 4 . 5 8 8 1}$ \\
\hline D & $\mathbf{4 9 . 0 5 1 9}$ & I & $\mathbf{6 4 . 6 1 2 7}$ & N & 5.4429 \\
\hline E & $\mathbf{6 1 . 1 7 2 6}$ & J & 8.1871 & O & 10.1408 \\
\hline
\end{tabular}




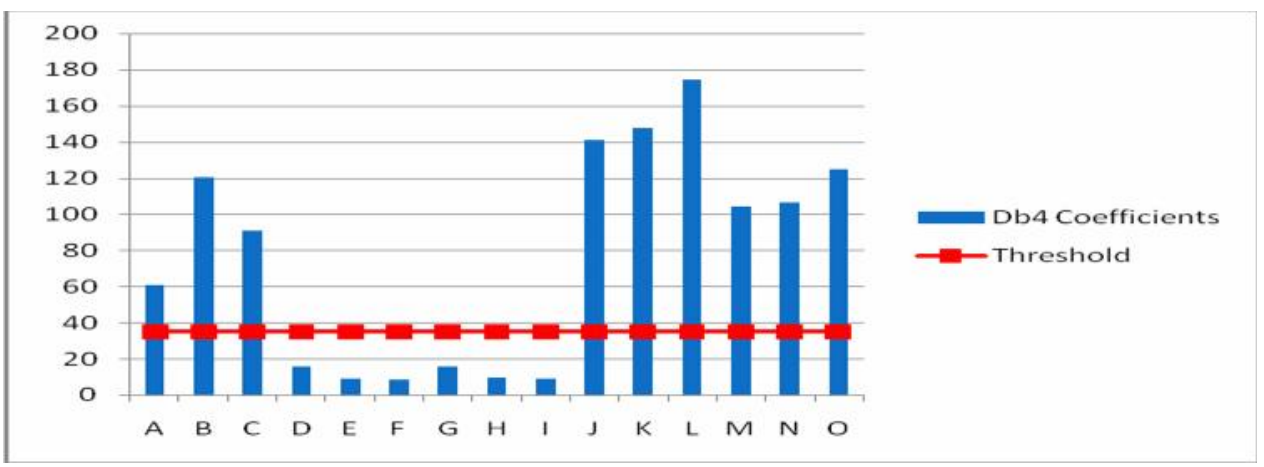

Figure 22. Db4 coefficients for 'ABC-g' fault at $85 \%$, 'JKL-g' fault at $30 \%$ and 'MNO-g' fault at $45 \%$ from bus-1

Table 18. Response of Db4WT for 'ABC-g' fault at $85 \%$, 'JKL-g' fault at $30 \%$ and 'MNO-g' fault at $45 \%$ from bus-1 with $\mathrm{R}_{\mathrm{f}}=$ $\mathrm{R}_{\mathrm{g}}=5$ and FIT $=0.35$ seconds

\begin{tabular}{|c|c|c|c|c|c|}
\hline Phase & Db4 Coefficients & Phase & Db4 Coefficients & Phase & Db4 Coefficients \\
\hline A & $\mathbf{6 0 . 8 8 5 8}$ & F & 8.3997 & K & $\mathbf{1 4 7 . 6 2 8 4}$ \\
\hline B & $\mathbf{1 2 0 . 4 5 9 8}$ & G & 15.6272 & L & $\mathbf{1 7 4 . 4 4 5 4}$ \\
\hline C & $\mathbf{9 0 . 6 0 6 5}$ & H & 9.2306 & M & $\mathbf{1 0 4 . 2 3 7 0}$ \\
\hline D & 15.4310 & I & 8.7487 & N & $\mathbf{1 0 6 . 1 7 1 3}$ \\
\hline E & 9.1411 & J & $\mathbf{1 4 1 . 1 6 5 9}$ & $\mathbf{O}$ & $\mathbf{1 2 4 . 6 3 9 8}$ \\
\hline
\end{tabular}

\section{Conclusion}

The daubechies-4 wavelet transform (Db4WT) is perceived to be very effectual under miscellaneous fault categories for the fifteen-phase transmission line. The first level Db4WT detail coefficients of the fifteen-phase fault currents are estimated. The fault factors of the simulation model are varied and it is revealed that the fault factors do not manipulate the fidelity of the $\mathrm{Db} 4$ wavelet transform. The results corroborate that the daubechies-4 wavelet transform has the competence to protect the fifteen-phase transmission line besides various fault categories. The future work is planned on execution of the proposed technique on a digital platform (preferably digital signal processor) and assessing the scheme for more practical conditions.

\section{References}

Abdullah G. A., 2018. Ultrafast transmission line fault detection using a DWT based ANN, IEEE Transactions on Industry Applications, Vol. 54, No. 2, pp. 1182-1193.

Adly A. R., Sehiemy R. A. E., Abdelaziz A. Y., and Ayad N. M. A., 2016. Critical aspects on wavelet transforms based fault identification procedures in HV transmission line, IET Generation, Transmission and Distribution, Vol. 10, No. 2, pp. 508517.

Gautam N., Ali S., and Kapoor G., 2018. Detection of fault in series capacitor compensated double circuit transmission line using wavelet transform, Proc. IEEE Int. Conf. Computing, Power and Communication Technologies (GUCON), pp. 769-773.

Gautam N., Kapoor G., and Ali S., 2018. Wavelet transform based technique for fault detection and classification in a $400 \mathrm{kV}$ double circuit transmission line, Asian Journal of Electrical Sciences, Vol. 7, No. 2, pp. 77-83.

Kapoor G., 2019. Detection and classification of single line to ground boundary faults in a $138 \mathrm{kV}$ six phase transmission line using Hilbert Huang transform, i-manager's Journal on Electrical Engineering, Vol. 12, No. 3, pp. $28-41$.

Kapoor G., 2019. A protection technique for series capacitor compensated $400 \mathrm{kV}$ double circuit transmission line based on wavelet transform including inter-circuit and cross-country faults, International Journal of Engineering, Science and Technology, Vol. 11, No. 2, pp. 1-20.

Kapoor G., 2019. Protection technique for series capacitor compensated three phase transmission line connected with distributed generation using discrete Walsh Hadamard transform, International Journal of Engineering, Science and Technology, Vol. 11, No. 3, pp. 1-10.

Kapoor G., 2019. Detection and classification of three phase to ground faults in a $138 \mathrm{kV}$ six-phase transmission line using Hilbert-Huang transform, JEA Journal of Electrical Engineering, Vol. 3, No. 1, pp. 1-11.

Kapoor G., 2018. Fault detection of phase to phase fault in series capacitor compensated six-phase transmission line using wavelet transform. Jordan Journal of Electrical Engineering, Vol. 4, No. 3, pp. 151-164.

Kapoor G., 2018. Six-phase transmission line boundary protection using mathematical morphology. Proceedings of the IEEE International Conference on Computing, Power and Communication Technologies (GUCON), pp. 857-861. 
Kapoor G., 2018. A contemporary discrete wavelet transform based twelve phase series capacitor compensated transmission line protection, International Journal of Engineering, Research and Technology, Vol. 7, No. 5, pp. 263-271.

Kapoor G., 2018. Discrete wavelet transform based technique to locate faults in three terminal transmission lines, Journal of Advanced Research in Electrical Engineering and Technology, Vol. 5, No. 3, pp. 1-8.

Kapoor G., 2018. Wavelet transform based fault detector for protection of series capacitor compensated three phase transmission line, International Journal of Engineering, Science and Technology, Vol. 10, No. 4, pp. 29-49.

Kapoor G., 2018. Wavelet transform based detection and classification of multi-location three phase to ground faults in twelve phase transmission line. Majlesi Journal of Mechatronic Systems, Vol. 7, No. 4, pp. 47-60.

Kapoor G., 2018. A fault location evaluation method of a $330 \mathrm{kV}$ three phase transmission line by using discrete wavelet transform, International Journal of Engineering, Design and Analysis, Vol. 1, No. 1, pp. 5-10.

Kapoor G., 2018. Detection of phase to phase faults and identification of faulty phases in series capacitor compensated six phase transmission line using the norm of wavelet transform, i-manager's Journal on Digital Signal Processing, Vol. 6, No. 1, pp. $10-20$.

Kapoor G., 2018. Six-phase transmission line boundary protection using wavelet transform. Proceedings of the $8^{\text {th }}$ IEEE India International Conference on Power Electronics (IICPE).

Kapoor G., 2018. A discrete wavelet transform approach to fault location on a $138 \mathrm{kV}$ two terminal transmission line using current signals of both ends, ICTACT Journal of Microelectronics, Vol. 4, No. 3, pp. 625-629.

Kapoor G., 2018. Mathematical morphology based fault detector for protection of double circuit transmission line, ICTACT Journal of Micro Electronics, Vol.4, No.2, pp. 589-600.

Kapoor G., 2018. Wavelet transform based fault detector for protection of series capacitor compensated three phase transmission line, International Journal of Engineering, Science and Technology, Vol. 10, No. 4, pp. 29-49.

Kapoor G., 2018. Protection scheme for double circuit transmission lines based on wavelet transform, ICTACT Journal of Micro Electronics, Vol. 4, No. 3, pp. 656-664.

Koley E., Verma K., and Ghosh S., 2017. A modular neuro-wavelet based non-unit protection scheme for zone identification and fault location in six phase transmission line. Neural Comput. \& Applications, Vol. 28, No. 6, pp. 1369-1385.

Koley E., Yadav A., Thoke A. S., 2014. A new single ended artificial neural network based protection scheme for shunt faults in six phase transmission line. International Transctions on Electrical Energy Systems, Vol. 25, No. 7, pp. 1257-1280.

Kumar R., Koley E., Yadav A. and Thoke A. S., 2014. Fault classification of phase to phase fault in six phase transmission line using Haar Wavelet and ANN. Proceeding of the IEEE International Conference on Signal Processing and Integrated Networks, pp. 5-8.

Kumar B. and Yadav A, 2017. Backup protection scheme for transmission line compensated with UPFC during high impedance faults and dynamic situations, IET Science, Measurement and Technology, Vol. 11, No. 6, pp. 703-712.

Ma J., Xiang X., Li P., Deng Z., and Thorp J. S., 2017. Adaptive distance protection scheme with quadrilateral characteristic for extremely high-voltage/ultra-high-voltage transmission line, IET Generation, Transmission and Distribution, Vol. 11, No. 7, pp. 1624-1633.

Namdari F. and Salehi M., 2017. A high-speed protection scheme based on initial current traveling wave for transmission lines employing mathematical morphology, IEEE Transactions on Power Delivery, Vol. 32, No. 1, pp. 246-253.

Rathore B. and Shaik A. G., 2017. Wavelet-alienation based transmission line protection scheme, IET Generation, Transmission and Distribution, Vol. 11, No. 4, pp. 995-1003.

Sharma N., Ali S. and Kapoor G., 2018. Fault detection in wind farm integrated series capacitor compensated transmission line using Hilbert Huang transform. Proceedings of the IEEE International Conference on Computing, Power and Communication Technologies (GUCON), pp. 774-778.

Sharma P., Kapoor G., and Ali S., 2018. Fault detection on series capacitor compensated transmission line using Walsh Hadamard transform, Proceedings of the IEEE International Conference on Computing, Power and Communication Technologies (GUCON), pp. 763-768.

Sharma P., Ali S., and Kapoor G., 2018. Wavelet transform approach for fault detection of three phase transmission line compensated with series capacitor, Asian Journal of Electrical Sciences, Vol. 7, No. 2, pp. 8-13.

Sharma K., Ali S., and Kapoor G., 2017. Six-phase transmission line boundary fault detection using mathematical morphology. International Journal of Engineering Research and Technology, Vol. 6, No. 12, pp. 150-154.

Som S., and Samantaray, S. R., 2018. Efficient protection scheme for low-voltage DC micro-grid, IET Generation, Transmission and Distribution, Vol. 12, No. 13, pp. 3322-3329.

Singh A. R., Patne N. R., Kale V. S., and Khadke P., 2017. Digital impedance pilot relaying scheme for STATCOM compensated TL for fault phase classification with fault location, IET Generation, Transmission and Distribution, Vol. 11, No. 10, pp. 2586-2598.

Tzelepis D., Dyśko A., Blair S. M., Oulis Rousis A., Mirsaeidi S., Booth C., and Dong X., 2018. Centralized bus bar differential and wavelet based line protection system for multi terminal direct current grids, with practical IEC-61869-compliant measurements, IET Generation, Transmission, Distribution, Vol. 12, No. 14, pp. 3578-3586. 
Taheri M. M., Seyedi H., and Ivatloo B. M., 2017. DT-based relaying scheme for fault classification in transmission lines using MODP, IET Generation, Transmission and Distribution, Vol. 11, No. 11, pp. 2796-2804.

Warathe S. and Patel R. N., 2015. Six phase transmission line over current protection by numerical relay, Proceeding of the IEEE International Conference on Advance Computing and Communication Systems, pp. 1-5.

\section{Biographical notes}

Gaurav Kapoor received B.E. in Electrical Engineering from University of Rajasthan, Jaipur, India and M. Tech. in Power System specialization from University College of Engineering, Rajasthan Technical University, Kota, India in 2011 and 2014, respectively. He is an Assistant Professor in the Department of Electrical Engineering, Modi Institute of Technology Kota, India. He has published more than forty five papers in various journals. He has also presented many research papers in national and international conferences. His research interests include power system digital protection.

Received October 2018

Accepted June 2019

Final acceptance in revised form July 2019 